Review

\title{
Application of Microbiome Management in Therapy for Clostridioides difficile Infections: From Fecal Microbiota Transplantation to Probiotics to Microbiota-Preserving Antimicrobial Agents
}

\author{
Chun-Wei Chiu ${ }^{1}$, Pei-Jane Tsai ${ }^{2}$, Ching-Chi Lee ${ }^{3,4} \mathbb{D}$, Wen-Chien Ko ${ }^{4,5, * \mathbb{D}}$ and Yuan-Pin Hung ${ }^{1,4,5, * \mathbb{D}}$ \\ 1 Department of Internal Medicine, Tainan Hospital, Ministry of Health and Welfare, Tainan 700, Taiwan; \\ bahamudo@gmail.com \\ 2 Department of Medical Laboratory Science and Biotechnology, National Cheng Kung University, \\ Medical College, Tainan 704, Taiwan; peijtsai@mail.ncku.edu.tw \\ 3 Clinical Medicine Research Center, National Cheng Kung University Hospital, College of Medicine, \\ National Cheng Kung University, Tainan 704, Taiwan; chichingbm85@gmail.com \\ 4 Department of Internal Medicine, College of Medicine, National Cheng Kung University Hospital, \\ Tainan 704, Taiwan \\ 5 Department of Medicine, College of Medicine, National Cheng Kung University, Tainan 704, Taiwan \\ * Correspondence: winston3415@gmail.com (W.-C.K.); yuebin16@yahoo.com.tw (Y.-P.H.)
}

Citation: Chiu, C.-W.; Tsai, P.-J.; Lee,

C.-C.; Ko, W.-C.; Hung, Y.-P.

Application of Microbiome

Management in Therapy for

Clostridioides difficile Infections: From

Fecal Microbiota Transplantation to

Probiotics to Microbiota-Preserving

Antimicrobial Agents. Pathogens 2021,

10, 649. https://doi.org/10.3390/

pathogens 10060649

Academic Editors: Valentina

Virginia Ebani and Luis M.

Cintas Izarra

Received: 26 March 2021

Accepted: 19 May 2021

Published: 24 May 2021

Publisher's Note: MDPI stays neutral with regard to jurisdictional claims in published maps and institutional affiliations.

Copyright: (c) 2021 by the authors. Licensee MDPI, Basel, Switzerland. This article is an open access article distributed under the terms and conditions of the Creative Commons Attribution (CC BY) license (https:// creativecommons.org/licenses/by/ $4.0 /)$.
Abstract: Oral vancomycin and metronidazole, though they are the therapeutic choice for Clostridioides difficile infections (CDIs), also markedly disturb microbiota, leading to a prolonged loss of colonization resistance to $C$. difficile after therapy; as a result, their use is associated with a high treatment failure rate and high recurrent rate. An alternative for CDIs therapy contains the delivery of beneficial (probiotic) microorganisms into the intestinal tract to restore the microbial balance. Recently, mixture regimens containing Lactobacillus species, Saccharomyces boulardii, or Clostridium butyricum have been extensively studied for the prophylaxis of CDIs. Fecal microbiota transplantation (FMT), the transfer of (processed) fecal material from healthy donors to patients for treating CDIs, combined with vancomycin was recommended as the primary therapy for multiple recurrent CDIs (rCDIs). Either probiotics or FMT have been utilized extensively in preventing or treating CDIs, aiming at less disturbance in the microbiota to prevent rCDIs after therapy cessation. Otherwise, many newly developed therapeutic agents have been developed and aim to preserve microbiota during CDI treatment to prevent disease recurrence and might be useful in clinical patients with rCDIs in the future.

Keywords: Clostridioides difficile; Clostridioides difficile infection; microbiome; probiotics; recurrence; fecal microbiota transplantation

\section{Disruption of Gut Microbiota after Antibiotic Exposure Results in Recurrent C. difficile Infection}

Clostridioides difficile, as the major cause of antibiotic-associated diarrhea, has clinical symptoms ranging from diarrhea to pseudomembranous colitis or toxic megacolon, with a mortality rate of up to 25-40\% [1-5]. In the "Clinical Practice Guidelines for Clostridioides difficile Infections (CDIs) in Adults and Children: 2017 Update" by the Infectious Diseases Society of America (IDSA) and Society for Healthcare Epidemiology of America (SHEA), vancomycin replaced metronidazole as the therapeutic choice for either mild-to-moderate or severe CDIs [6]. Nevertheless, oral vancomycin and metronidazole markedly disturbed the microbiota, which resulted in the dense colonization by vancomycin-resistant Enterococcus, Klebsiella pneumoniae, and Escherichia coli, and, more importantly, the prolonged loss of colonization resistance to $C$. difficile [7]. Although antimicrobial resistance is not clinically problematic, treating CDIs with metronidazole and vancomycin is associated with a high 
treatment failure rate and recurrence rate [8]. For recurrent CDIs (rCDIs), according to the Clinical Practice Guidelines by IDSA/SHEA, oral vancomycin is still the drug of choice, but the rate of the sequential recurrence is as high as $22.6-41.8 \%$ despite successful treatment with vancomycin [9].

There are more than 1000 distinct species of bacteria inhabited in the human gastrointestinal system with a symbiotic relationship, with the collection of microbes called the "microbiota" $[10,11]$. The relative high susceptibility to infections in neonates might be due to the immaturity of the immune system, and the mechanism is probably due to the relative "immature" microbiota [12]. By colonizing adult germ-free mice with the cecal contents of neonatal mice, the microbiota is unable to prevent colonization by two bacterial pathogens, including Citrobacter rodentium, a natural pathogen of mice that is used to model human infections with the enteropathogenic E. coli and Salmonella typhimurium that cause mortality in neonates [12]. The lack of colonization resistance was correlated to the absence of Clostridiales in the neonatal microbiota, and the administration of Clostridiales could protect neonatal mice from pathogen infection [12]. Thus, the component of gut microbiota is associated with the immunity of the host.

The colonized microbiota in the mammalian gut occurs shortly after birth and remains with little fluctuation throughout the host's life; the microbiota is primarily composed of five bacteria phyla in healthy adults: Firmicutes (79.4\%), Bacteroidetes (16.9\%), Actinobacteria $(2.5 \%)$, Proteobacteria (1\%), and Verrucomicrobia (0.1\%) [13]. A wide range of host or environment factors, including diet, sleep, and disease, can alter the microbiota diversity and abundancy $[10,11]$. Of note, the rise of antimicrobial agent-resistant pathogens, combined with reduction of microbiota diversity after antibiotic treatment, has become a significant challenge in the fight against all kinds of invasive infections worldwide [14]. To prevent the disruption of the microbiota, some microbiota-based treatments, such as fecal microbiota transplantation (FMT) and the administration of probiotics, have been used to "rescue" the disrupted microbiota [14] (Figure 1).

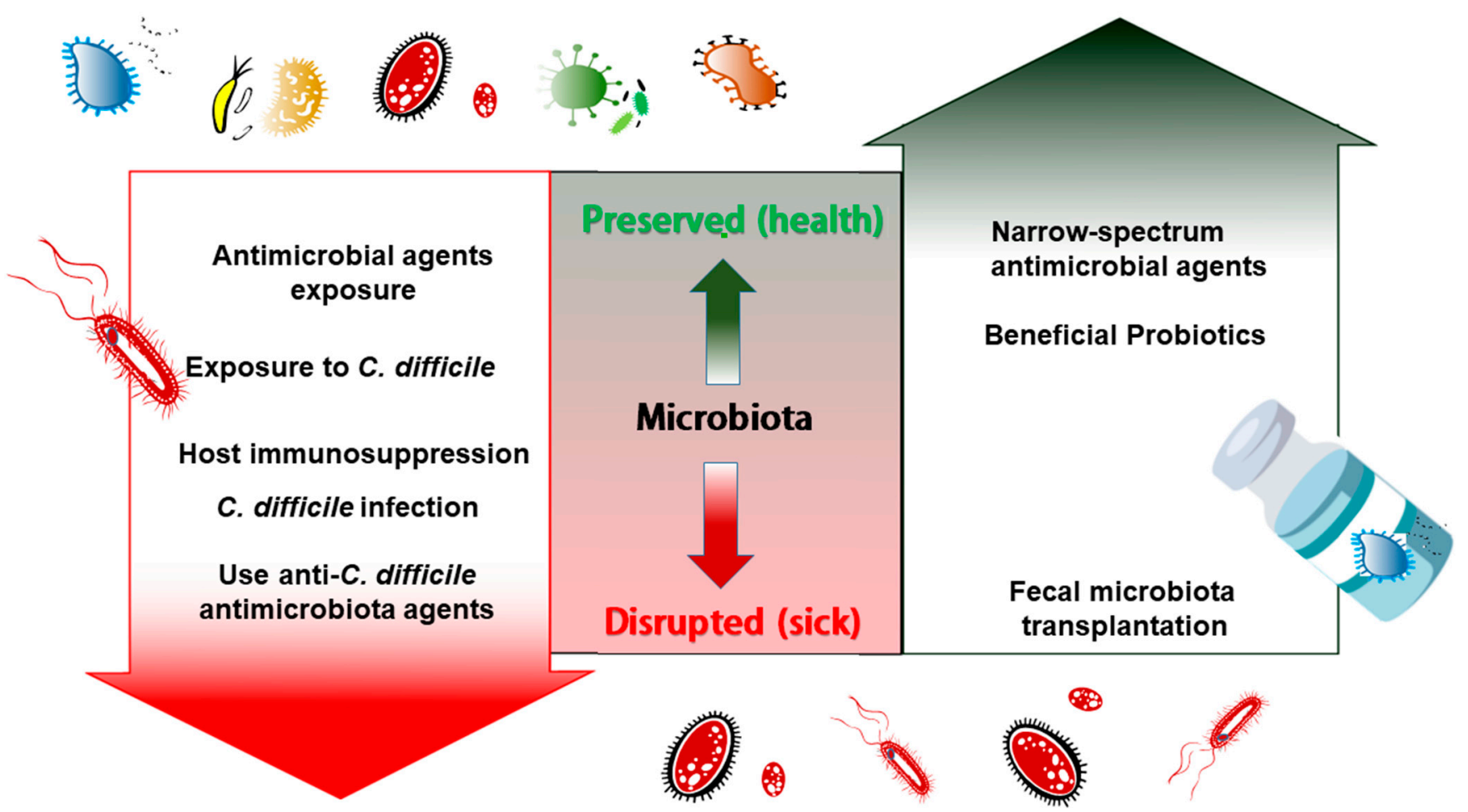

Figure 1. Fecal microbiota transplantation for C. difficile infection therapy.

FMT, the transfer of (processed) fecal material from healthy donors to CDI patients, combined with vancomycin have been recommended as the primary therapy for mul- 
tiple rCDIs [15] (Table 1). To simplify the influence of FMT on gut microbiota, studies among specific populations, such as groups with malignancy or inflammatory bowel disease, are not discussed in this review [16]. Since the poor bacterial diversity is correlated with rCDIs in clinical patients, the efficacy of FMT in preventing rCDIs has been correlated with the restoration of the disturbed and poor diversity of gut microbiota due to the disruption by antibiotic exposures $[17,18]$, for example, replanting the genera of Bacteroidetes [16,19-25], Firmicutes [23,25], Faecalibacterium [16,26], or Bifidobacterium [27], and conveniently decreasing Proteobacteria $[22,25,28]$, Enterobacteriaceae $[29,30]$, or bacteria harboring antibiotic-resistant genes within the microbiota [25].

The diverse change in microbiota after FMT was noticed, which might depend on the different composition of microbiota of the donor population, different donor ages, or different FMT methods [22,23,27,31,32]. For all successful FMT treatments with the resolution of rCDI symptoms and a negative $C$. difficile toxin test within 4-12 weeks after FMT, the genomic analysis of donor microbiota showed that the Bacteroidetes-to-Fermicutes ratio did not reveal a significant difference among donors with different ages [32]. However, the relative abundance of phylum Actinobacteria and family Bifidobacteriaceae was notably reduced in donors of more than 60 years of age [32]. A FMT study that consisted of the elderly with rCDIs revealed that FMT resulted in a marked improvement in all clinical parameters and overall microbiota diversity, but this response was less vigorous than the younger group [28]. Additionally, in the microbiota analysis, Firmicutes did not change markedly, but Proteobacteria decreased significantly in post-FMT samples among the elderly patients experiencing rCDIs [28].

There are numerous ways of performing FMT, including nasojejunal tube [21,22,30], colonoscopy $[18,20-22,25,30,33]$ and encapsulated oral form $[19,20,23]$. The way of performing FMT might affect the microbiota distribution [20]. In a randomized trial of adults with $\geq 3$ episodes of rCDIs who received encapsulated lyophilized fecal microbiota or frozen FMT by enema, the rCDI was prevented equally among the capsule group and FMT enema group ( $84 \%$ vs. $88 \%$, respectively, $p=0.76$ ). Although both products notably normalized the diversity of fecal microbiota, the lyophilized orally administered product was less effective in replanting Bacteroidia and Verrucomicrobia classes, compared to the frozen product via enema, and it was likely that there were some damaging effects of gastric acid, bile salts, and digestive enzymes during the upper gastrointestinal transit for the orally administered FMT product [20].

The colonization of Bacteroidetes [16,19-25], Firmicutes [23,25], Faecalibacterium [16,26], or Bifidobacterium [27] were found to be decreased during the initial CDIs and rCDIs after successful FMT. In a cohort with a long-term (up to 409 days) follow-up, all patients who were clinically recovered and free of CDIs were characterized by increased members of the genera Bacteroides, Parabacteroides, and Faecalibacterium throughout the year in their fecal microbiota [19]. In a prospective study dealing with rCDI children, FMT successfully prevented rCDI episodes for at least 3 months, along with significantly increased levels of Bacteroidetes [21]. Among rCDI patients, FMT reduced beta diversity differences between the donors and recipients and increased in relative abundance of $F$. prausnitzii [16]. Of patients receiving FMT for rCDIs, symptoms resolved in $71.4 \%$ of cases treated with the fecal bacterial composition dominated by Firmicutes, Bacteroidetes, and Proteobacteria, and were remarkably stable over time after FMT [22]. With encapsulated oral intake FMT, taxa within the Firmicutes showed rapid increases in relative abundance that did not vary significantly over time. Bacteroidetes taxa only showed significant increases in abundance after one-month post-FMT among patients with rapid decline in the rCDI symptoms [23]. Among patients receiving FMT using colonoscopy in Germany, the healing rate of CDIs was $94 \%$, and in all patients successfully treated with FMT, their microbiota revealed elevated Lactobacillaceae, Ruminococcaceae, Desulfovibrionaceae, Sutterellaceae, and Porphyromonodacea [33]. In a high-throughput microbiota profiling using a phylogenetic microarray analysis for rCDI patients, FMT reverted the patients' bacterial community 
to become dominated by Clostridium clusters IV and XIVa and there was an increase in Bacteroidetes [24].

No matter the composition of donor's microbiota or the ways of performing FMT, donor-derived Bacteroidetes, Firmicutes, or Bifidobacterium can colonize rCDI patients who were treated successfully with FMT for more than one year, and accordingly, FMT may have long-term consequences for the recipient's microbiota and health [22-24,27,31].

Proteobacteria $[22,25,28]$, Enterobacteriaceae $[29,30]$ and the bacteria harboring antibiotic resistance genes within the microbiota [25] were mostly increased during CDIs and decreased after FMT. In a prospective, observational study of rCDI children, FMT successfully prevented rCDIs for a minimum of 3 months post-FMT, with no major adverse effects, along with the significantly decreased level of Proteobacteria [21].

Some commercialized products have been developed for FMT [34]. To utilize FMT with a high abundance of non-resistant species to displace antibiotic-resistant organisms from the recipient's microbiome, RBX2660, a liquid suspension of donor microbiota, has recently been deployed to treat rCDIs [34]. RBX2660 was found to aid in the successful prevention of rCDIs, correlated with the taxonomic convergence of patient microbiota to the donor microbiota, and also dramatically reduced the abundance of antibiotic-resistant Enterobacteriaceae [34].

The mechanisms of FMT to effectively prevent or treat CDIs by modulating microbiota were proposed to be through the influence on the metabolism of certain bile acids that affect germination or vegetative growth of $C$. difficile [31,35-38]. Patients with CDIs exhibited significantly lower fecal levels of secondary bile acids and higher levels of primary bile acids [31]. In sum, the FMT mechanism might include microbiota-associated bile salt hydrolases (BSHs) [35], the bile acid-farnesoid $X$ receptor-fibroblast growth factor pathway [36], and bile acid-inducible (bai) operon [37]. Loss of gut microbiota-derived BSHs predisposes individuals to CDIs by perturbing the gut bile metabolism, and the restoration of gut BSH functionality has contributed to efficacies of FMT in treating rCDIs [35]. FMT for rCDIs is accompanied by a significant, sustained increase in circulating levels of FGF19 and in the reduction of FGF21, which are critical pathway signals of the bile acid-farnesoid $X$ receptor-fibroblast growth factor, which are important pathways in the restoration of gut microbiota and bile acid profiles [36]. A single bai operon (baiCD), majorly found in C. scindens and $C$. hiranonis, was recently reported to protect against $C$. difficile colonization, and is a required gene for $7 \alpha$-dehydroxylation, which is a key step in the transformation of primary to secondary bile acids. The rCDI patients were baiCD-negative at baseline, but baiCD turned positive after successful FMT from a baiCD-positive donor [37].

Other than bile acid, sustained increases in the levels of the short chain fatty acids (SCFAs), including butyrate, acetate, and propionate were observed in FMT recipients, and these metabolites that increased following FMT were associated with the repletion of bacteria classified within the Lachnospiraceae, Ruminococcaceae, and unclassified Clostridial families [38].

Some treatment failures were reported in FMT for CDI. In a study that prospectively treated recurrent CDI with FMT by colonoscopy in Italy, only 44 (69\%) were cured by a single fecal infusion, whereas the other 20 (31\%) needed repeat infusions [39]. At multivariate analysis, severe CDI (OR 24.66) and inadequate bowel preparation (OR 11.53) were found to be independent predictors of failure after a single fecal infusion [39]. In the United States, the primary cure rate of FMT at 3 months in a multicenter study toward CDI was as low as $58.7 \%$ in solid organ transplant recipients, which was lower in patients with other co-morbidity, including $25 \%$ of patients with underlying inflammatory bowel disease who had worsening disease activity, while $14 \%$ of cytomegalovirus-seropositive patients had reactivation [40]. Predictors of failing for a single FMT included inpatient status, severe and fulminant CDI, presence of pseudomembranous colitis, and use of non-CDI antibiotics at the time of FMT [40]. Patients with high risk for FMT failure should be monitored closely and might need repeat FMT. 
Table 1. Examples of influence on microbiota when treating adult patients with Clostridioides difficile infections (CDIs) with fecal microbiota transplantation (FMT) *.

\begin{tabular}{|c|c|c|c|c|c|c|c|}
\hline Author & Year & Country & $\begin{array}{l}\text { Recipient } \\
\text { Numbers }\end{array}$ & Procedures of FMT & Effects on CDIs & Influence on Receipt Microbiota & Reference \\
\hline Amy Langdon et al. & 2013 & USA & 29 & $\begin{array}{l}\text { RBX2660, a liquid suspension of } \\
\text { donor microbiota via enema }\end{array}$ & $\begin{array}{l}41.3 \% \text { patients had no recurrence after a } \\
\text { single dose; others had a recurrence and } \\
\text { required a repeat dose }\end{array}$ & $\begin{array}{l}\text { Reduced the abundance of antibiotic-resistant Enterobacteriaceae in } \\
\text { two months }\end{array}$ & [34] \\
\hline Yang Song et al. & 2013 & USA & 14 & $\begin{array}{l}\text { Combined enteroscopy and } \\
\text { colonoscopy }\end{array}$ & rCDI treated successfully by FMT & $\begin{array}{c}\text { Members of Streptococci or Enterobacteriaceae were significantly decreased } \\
\text { and putative butyrate producers, such as Lachnospiraceea and } \\
\text { Ruminococcaceae, were significantly increased. }\end{array}$ & [30] \\
\hline Sudhir K Dutta et al. & 2014 & USA & 27 & $\begin{array}{l}\text { Combined enteroscopy and } \\
\text { colonoscopy }\end{array}$ & All recipients had clinical resolution & $\begin{array}{l}\text { Increased microbial diversity, increasing proportions of Lachnospiraceae } \\
\text { (phylum Firmicutes) and reducing proportions of Enterobacteriaceae. }\end{array}$ & [29] \\
\hline Anna M. Seekatz et al. & 2014 & USA & 6 & Colonoscopy & $\begin{array}{l}\text { All recipients had clinical resolution of CDI } \\
\text { following FMT and were recurrence-free up } \\
\text { to six months. }\end{array}$ & $\begin{array}{l}\text { Metabolites that increased following FMT were associated with bacteria } \\
\text { classified within the Lachnospiraceae, Ruminococcaceae, and unclassified } \\
\text { Clostridiales families. }\end{array}$ & [38] \\
\hline Vijay Shankar et al. & 2014 & Finland & 3 & Colonoscopy & All patients had reduced diarrheal symptoms & Rich in members of Blautia, Coprococcus, and Faecalibacterium. & [26] \\
\hline Michael Mintz et al. & $\begin{array}{l}2013- \\
2016\end{array}$ & USA & 11 & Colonoscopy & No rCDI after one year of follow-up & $\begin{array}{l}\text { Reduced beta diversity differences between the donors and recipients, and } \\
\text { increased in relative abundance of } F \text {. prausnitzii. }\end{array}$ & {$[16]$} \\
\hline P C Konturek et al. & $2014-$ & German & 17 & Colonoscopy & $\begin{array}{l}\text { The healing rate of CDI was } 94 \% \text {. In all } \\
\text { successfully treated patients no recurrent CDI } \\
\text { was observed during follow-up (16 months) }\end{array}$ & $\begin{array}{c}\text { Elevated abundance of beneficial bacterial species such as Lactobacillaceae, } \\
\text { Ruminococcaceae, Desulfovibrionaceae, Sutterellaceae, and } \\
\text { Porphyromonodacea after FMT. }\end{array}$ & [33] \\
\hline Jonna Jalanka et al. & 2016 & Finland & 14 & $\begin{array}{l}\text { The fecal suspension } \\
\text { was infused into the cecum }\end{array}$ & $\begin{array}{l}\text { The FMT treatment cleared rCDI from } \\
\text { all patients }\end{array}$ & $\begin{array}{l}\text { Dominated by Clostridium clusters IV and XIVa, with } \\
\text { increased Bacteroidetes. }\end{array}$ & [24] \\
\hline Braden Millan et al. & 2016 & Canada & 20 & Colonoscopy & FMT resulted in a resolution of symptoms & $\begin{array}{l}\text { Decreased number and diversity of antibiotic resistance genes and increased } \\
\text { Bacteroidetes and Firmicutes with reduced Proteobacteria. }\end{array}$ & [25] \\
\hline Mohit Girotra et al. & 2016 & USA & 29 & $\begin{array}{l}\text { Combined colonoscopy and } \\
\text { nasojejunal tube }\end{array}$ & $\begin{array}{l}\text { Marked improvement in all } \\
\text { clinical parameters }\end{array}$ & Microbiota diversity increased with Proteobacteria decreased. & [28] \\
\hline Christopher Staley et al. & 2016 & USA & 39 & $\begin{array}{l}\text { Prepared as capsule and } \\
\text { oral intake }\end{array}$ & Rapid resolution of rCDI symptoms & $\begin{array}{l}\text { Taxa within the Firmicutes showed rapid increases in relative abundance } \\
\text { and did not vary significantly over time. Bacteroidetes taxa only showed } \\
\text { significant increases in abundance after one-month post-FMT. }\end{array}$ & [23] \\
\hline $\begin{array}{c}\text { Adrián } \\
\text { Camacho-Ortiz et al. }\end{array}$ & 2017 & $\begin{array}{l}\text { United } \\
\text { Kingdom }\end{array}$ & 7 & $\begin{array}{l}\text { Either colonoscopy or } \\
\text { nasojejunal tube }\end{array}$ & $\begin{array}{l}\text { Symptoms resolved in } 57.1 \% \text { patients after the } \\
\text { first FMT and in } 71.4 \% \text { after the second dose. }\end{array}$ & $\begin{array}{l}\text { The bacterial composition was dominated by Firmicutes, Bacteroidetes, and } \\
\text { Proteobacteria at all-time points, and the microbiota were remarkably stable } \\
\text { over time. }\end{array}$ & [22] \\
\hline Z D Jiang et al. & 2017 & USA & 72 & $\begin{array}{l}\text { Randomized to receive fresh, } \\
\text { frozen or lyophilized FMT } \\
\text { product via colonoscopy }\end{array}$ & $\begin{array}{l}\text { Overall resolution of CDI was } 87 \% \text { during } 2 \\
\text { months of follow-up. }\end{array}$ & $\begin{array}{l}\text { Microbial diversity was reconstituted by day } 7 \text { with fresh or frozen product; } \\
\text { by } 30 \text { days with lyophilized material. }\end{array}$ & [18] \\
\hline Shaaz Fareed et al. & 2017 & USA & 15 & $\begin{array}{l}\text { Either colonoscopy or } \\
\text { nasojejunal tube }\end{array}$ & $\begin{array}{l}\text { Prevented recurrent CDI for minimum of } 3 \\
\text { months post-FMT in all patients. }\end{array}$ & Increased levels of Bacteroidetes and decreased levels of Proteobacteria & [21] \\
\hline Jillian R-M Brown et al. & 2018 & Ireland & 10 & $\begin{array}{l}\text { Both } \\
\text { esophago-gastro-duodenoscopy } \\
\text { and full colonoscopy }\end{array}$ & $\begin{array}{l}\text { Nine out of ten patients } \\
\text { improved clinically and remained C. difficile } \\
\text { toxin negative for between } 6 \text { months and } 2 \\
\text { years after a single FMT }\end{array}$ & $\begin{array}{l}\text { FMT moves the microbiota of recipients towards that of the donor and } \\
\text { improves bacterial diversity. }\end{array}$ & [31] \\
\hline Zhi-Dong Jiang et al. & 2018 & USA & 65 & $\begin{array}{l}\text { Encapsulated lyophilized fecal } \\
\text { microbiota }(n=31) \text { or frozen } \\
\text { FMT }(n=34) \text { by enema. }\end{array}$ & $\begin{array}{l}\text { CDI recurrence rate after FMT: } 84 \% \text { in capsule } \\
\text { group; } 88 \% \text { in FMT enema group, } p=0.76\end{array}$ & $\begin{array}{l}\text { Both products normalized fecal microbiota diversity while the lyophilized } \\
\text { orally administered product was less effective in repleting Bacteroidia and } \\
\text { Verrucomicrobia classes compared to frozen product via enema. }\end{array}$ & [20] \\
\hline Christopher Staley et al. & 2019 & USA & 18 & $\begin{array}{l}\text { encapsulated lyophilized fecal } \\
\text { microbiota orally }\end{array}$ & All recovered clinically and were free of CDI & $\begin{array}{c}\text { Members of the genera Bacteroides, Parabacteroides, and Faecalibacterium were } \\
\text { positively correlated with donor similarity. }\end{array}$ & [19] \\
\hline Hanne Jouhten et al. & 2020 & Finland & 13 & ND & $\begin{array}{l}\text { Only recipients with rCDI successfully } \\
\text { treated with FMT were included, }\end{array}$ & $\begin{array}{l}\begin{array}{l}\text { Specific donor-derived bifidobacterium can colonize rCDI patients for at least } \\
\text { one year. }\end{array}\end{array}$ & [27] \\
\hline
\end{tabular}

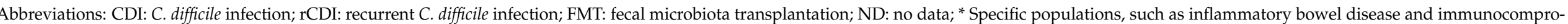
mised patients, were not listed. 
There were some adverse events related to FMT that should be taken into considerations, including nausea, diarrhea, bloating, and abdominal cramping [10]. Of note, two patients with the same stool donor experienced E. coli bacteriemia, which lead to the death of one of the patients [41]. Thus, the selection of appropriate fecal donors and recipients is an important issue in performing FMT.

\section{Probiotics Supply to Restore the Disturbed Microbiota in CDI}

An alternative for CDI therapy comprises the delivery of beneficial (probiotic) organisms into the intestinal tract to restore the microbial balance. The theoretical foundation for this approach is that specific components of the microbiota, the microorganisms that normally colonize the body, can protect the gut from some pathogenic bacteria. Nevertheless, during antibiotic treatment for other infectious diseases, the protective intestinal microflora is damaged, which leads to the $C$. difficile proliferation and infection. The initial antibiotic exposure leaves the host susceptible to colonization and subsequent infection by $C$. difficile. A so-called "second-hit" to the intestinal microbiota occurs when the infected host is treated with metronidazole or vancomycin, further destroying susceptible microbiota [42]. Probiotic microorganisms, such as Lactobacillus rhamnosus GG. or Saccharomyces boulardii, have been studied for the prophylaxis or treatment of CDIs with moderate certainty evidence in the meta-analysis [43].

Bifidobacterium are a genus of Gram-positive, nonmotile, often branched anaerobic bacteria as ubiquitous residents of the gastrointestinal tract [44]. Supernatants from $b i$ fidobacteria isolated from healthy infants had the ability to inhibit $C$. difficile growth and adhesion to enterocytes [45]. Consumption of B. bifidum modulates the dominant intestinal bacterial taxa in healthy adults [46]. The efficacy of a mixture of Lactobacillus species in treating or preventing CDIs has been proven in many clinical trials [47-50]. A four-strain oral probiotic capsule containing L. acidophilus NCFM, L. paracasei Lpc-37, B. lactis Bl-07, and $B$. lactis Bl-04 has been used as the adjunct probiotic with significant improvement in diarrhea outcomes in patients with CDIs [47]. The consumption of L. acidophilus (CL1285), L. casei (LBC80R), and L. rhamnosus CLR2 combination (Bio-K+) was reported to diminish the CDI incidence and remained at low mean levels of 2.3 cases per 10,000 patient days among adult inpatients treated with antibiotics [48]. L. plantarum $299 \mathrm{v}$ could reduce the CDI incidence from $1.21 \%$ to $0.11 \%$ among hospitalized patients with comorbid nephrology or transplantation disease [49]; L. casei, L. bulgaricus, and Streptococcus thermophiles could prevent the CDI with an absolute risk reduction of $17 \%(7-27 \%)$ among hospital patients taking antibiotics [50]. Taken jointly, the evidence from these clinical trials suggests that the Lactobacillus species serves as an effective and safe probiotic in preventing CDI or its recurrence, but the role of Lactobacillus species as adjuvant therapy for CDIs remains unclear [47-50].

S. boulardii, as one kind of yeast probiotics, was characterized by its minimum effect on normal microbiota in healthy humans, whereas, in contrast, it could restore antibioticdisrupted microbiota rapidly [51]. S. boulardii CNCM I-745 significantly reduced cecal tissue damage, NF- $\kappa$ B phosphorylation, and TNF $\alpha$ protein expression caused by CDIs in the hamster model [52]. Among patients with CDIs who received high-dose vancomycin therapy, S. boulardii treatment could reduce the recurrence rate of CDIs [53]. In another CDI study, treatment with $S$. boulardii significantly reduced its recurrence risk (relative risk, 0.43) [54]. Currently, S. boulardii is the most commonly used of the probiotic mixture regimens for the CDI prophylaxis [43].

Some of the Bacteroides genus have been found to be capable of modulating microbiota, inhibiting $C$. difficile, and thus serving as surrogates for probiotics for antibiotic-associated diarrhea [55,56]. B. fragilis strain ZY-312 could increase the species Akkermansia muciniphila, which is an important human intestinal mucin-degrading bacterium in the microbiota and against CDIs, possibly by resisting its colonization and improving the integrity and function of the gut barrier [56]. B. thetaiotaomicron could significantly reverse the decreased Bacteroidetes levels as well as the increased Proteobacteria and Verrucomicrobiota levels, 
thus suppressing C. difficile in the gut [55]. The safety of using Bacteroides genus as surrogates for probiotics for antibiotic-associated diarrhea warrants further evaluation, since many Bacteroides genus could be invading pathogens in clinical patients $[55,56]$.

C. butyricum, facultative, and strictly anaerobic bacteria are progressively colonized in the neonate's intestine following birth [57]. In the rat model, the cytotoxin titer of $C$. difficile in rat feces decreased after treatment with C. butyricum [58]. C. butyricum, compared to the placebo, decreased the rate of antibiotic-associated diarrhea in pediatric patients from $59 \%$ to $5 \%$, which was associated with an increase in the level of anaerobes and prevented the decrease in the level of Bifidobacterium species [59]. C. butyricum, combined with S. faecalis and Bacillus mesentericus, prevented CDIs with a crude odds ratio of 0.074 among elderly patients who underwent proximal femoral fracture surgery [60]. The evidence of C. butyricum as an adjuvant therapeutic choice for CDIs is still lacking.

Recently, the mixture regimens containing Lactobacillus species, S. boulardii, or C. butyricum have been extensively studied for CDI prophylaxis $[43,60]$. The efficacy of the probiotic mixture for treating or preventing CDIs has been demonstrated, which was supposed to be through the modulation of gut microbiota; although, the influence of the single component of mixture regimens on microbiota was illustrated, the overall effect of the probiotic mixture in gut microbiota was not demonstrated [43,47-50,60].

There were no head-to head randomized clinical trials to compare the efficacy of two different probiotics. Thus, it is difficult to tell if one kind of probiotics are superior to another ones. Nevertheless, multi-strain probiotics (mixture regimen) might be more useful than single-strain options because of synergy and additive effects among the individuals with CDI in modulation of the immune system and gut microbiota [43,60].

Some debates exist in the use of probiotics. First, the fed probiotic bacteria could be detected in stool samples of all participants when consuming the probiotics; however, the probiotic bacteria was found in the colonic mucosa in only some participants [61,62]. The transient engraftment was dependent on the microbiome composition of the participants, which was quite different from the more uniform results obtained from the study of germfree mice [61,62]. Selecting appropriate probiotics on the basis of the composition of the microbiota of the recipient, the "target therapy" might be the goal of development in the future.

Though the beneficial effect of probiotics in preventing CDI has been illustrated, there are still some concerns regarding their safety, including infections or inflammatory/ fatal effects derived from toxins produced either by the probiotic strains or by possible bacterial contaminants [10]. Of note, Lactobacillus infection after taking probiotics products contain Lactobacillus spp. had been reported in some relatively immunocompromised patients [63-65]. These immunocompromised patients were at higher risk of developing CDI, and the use of probiotics to prevent CDI in these group of patients should be approached more carefully.

\section{Therapeutic Agents Preserving Microbiota during $C$. difficile Infection Treatment}

Many newly developed therapeutic agents are aimed at preserving microbiota during CDI treatment to prevent disease recurrence; for this purpose, two major kinds of therapeutic strategy were investigated: first, the development of narrow-spectrum antimicrobial agents, such as fidaxomicin [66-69], ridinidazole [70,71], or cadazolid [72,73]; second, developing antimicrobial agents specifically targeting some distinct structure of $C$. difficile, such as anti-sense antimicrobial agents [74,75], anti-toxin antibodies [76,77], and agents targeting the pathway of bacterial fatty acid synthesis [78].

Fidaxomicin, a minimally absorbed macrocyclic antibiotic, as well as vancomycin, are both drugs of choice for CDI treatment, but the former has less disturbance in the microbiota and, thus, is associated with less recurrent rates compared to vancomycin [9,66-69]. In the mice model, fidaxomicin reduced the proportion of Clostridial growth to a lesser extent, but increased that of Bacteroidia, and it resulted in less disturbance in microbiota diversity [66]. The lesser impact on the microbiota composition of fidaxomicin, compared to vancomycin, 
promoted faster microbial recovery in the gut, which had more colonization resistance to C. difficile, and thus, compared with vancomycin, achieved a more sustained clinical cure after 30 days (OR 1.62, $p=0.030)$ and less recurrent rate (11\% vs. $23 \%)$ after the end of treatment for CDI patients [67-69].

Ridinilazole, a narrow-spectrum antibiotic, with a non-inferior efficacy compared to vancomycin, had almost no disturbance in the gut microbiota, including several Bacteroidaceae and Clostridiaceae families, maintained the intestinal bile acid profile, and was associated with a lowered risk of recurrence in a phase 2 trial $[70,71]$.

Cadazolid, a novel quinoxolidinone antibiotic developed for treating CDI, had noninferiority for clinical cure compared to vancomycin in the phase 3 trial, with limited inhibition of the gut microflora, including the B. fragilis group and Lactobacillus spp. However, it is a pity, except for Bifidobacterium spp. [72,73].

Anti-sense antimicrobial agents, which means using the complementary binding of a modified anti-sense oligonucleotide (ASO) to a specific messenger ribonucleic acid (mRNA) in treating CDIs, has been investigated [74,75]. A group of 2'-O-methyl phosphorothioate gamer ASOs targeting five essential $C$. difficile genes achieved nanomolar minimum inhibitory concentrations for $C$. difficile [75]. The high specificity of the ASO for its target mRNA strengthens the binding of ASOs to its target mRNA, and improves specificity without offending microbiota [74,75].

The monoclonal antibody combination of actoxumab and bezlotoxumab, which bind to the receptor binding (known as combined repetitive oligopeptides (CROPs)) domains of $T c d A$ and $T c d B$, respectively, was examined in treatment for primary or recurrent CDIs. Notably, because the recurrence rate was significantly lower in CDI patients treated with bezlotoxumab alone than those with the placebo in the phase 3 trial [79], the efficacies for reducing the recurrence rate by actoxumab-bezlotoxumab treatment might be only due to the effect of bezlotoxumab on facilitating normalization of the gut microbiota [77]. Another oral product delivered from the ovine polyclonal antibody and targeted toward C. difficile toxins successfully neutralized toxin production and did not interfere with the colonic microbiota in an in vivo hamster model and an in vitro human colon model, but its efficacies were still limited in pre-clinical models [76].

Enoyl-acyl carrier protein (ACP) reductase II (FabK) is a critical rate-limiting step within the synthesis pathway of FAS-II bacterial fatty acid, which supplies precursory component phospholipids found in bacterial cytoplasmic and spore-mediated membranes, as well as being essential in C. difficile. More importantly, it is structurally and mechanistically distinct from other isozymes found in gut microbiota species that make C. difficile FabK $(\mathrm{CdFabK})$ an attractive narrow-spectrum target [78]. Though the FabK enzyme serves a potential role for the narrow-spectrum anti-C. difficile target, the related antimicrobial agents are still under investigation [78].

\section{Experimental C. difficile Animal Models for Microbiota Analysis}

To analyze the microbiota change during CDI, some germ-free or gnotobiotic animal models have been used [12,80-82]. Germ-free mice, which lack all microorganisms and allow for the transfer of selective bacterial species or whole fecal microbiota, serve as a completely blank microbial background to analyze the association of gut microbes with the host $[80,82]$. The transfer of human feces to germ-free mice has been applied to create a humanized gnotobiotic mouse mode since the 1980s, which was a revolutionary strategy to formulate in vivo systems of the human microbiota $[81,83]$. Inoculation of feces from a human donor into adult gnotobiotic recipient mice resulted in colonization by several strains from the donor that form an effective barrier against $C$. difficile $[81,83]$. Later, the use of rats implanted with human fecal microbiota were used as a model for studying the effects of diet on the human gut microflora $[82,84]$. Up to now, these rodents implanted with human microbiota have been considered the gold standard and cornerstone for establishing the causal role of microbiome alterations linked to human disease, with the advantages including: 1. they can be used to analyze the correlation between the phenotype and the 
environmental factors; 2 . they can be used to establish a causal association between altered microbiomes and diseases of the human host; and 3. they represent a platform to apply integrated "omics" approaches to identify the causal components of altered microbiomes that drive disease $[85,86]$.

Later, other improved animal models that are better mimics of human physiology, such as pigs and primates, were proposed [86]. Saul Tzipori et al. developed a reproducible piglet model for acute or chronic CDI with characteristic pseudomembranous colitis [87]. Presence of toxins in feces, body fluids, and serum, and a significant elevation of IL-8 in piglets with severe disease were noted, which suggested piglets to be a suitable animal model for investigating the role of virulence attributes, drug efficacy, and the evaluation of vaccine candidates [87]. Though pigs and primates are improved models, their greater cost can be constraining [86].

A critical challenge for developing animal models for microbiota analysis is the variances in the input microbiota from human donor feces, since there is a great influence of environmental factors on the differences in bacterial diversity and abundance in microbiota of donors [82]. Since not all humanized animal microbiota models can accurately represent different populations, selecting appropriate human fecal samples for the representative studies is still a task for microbiota analysis in animal models [82].

Another important issue in conducting animal models for microbiota analysis is the taxa that do colonize in animal models with human microbiota implants might differ substantially from those found in the human donors [86]. For example, though human and murine gut floras share $90 \%$ and $89 \%$ similarities in phyla and genera, respectively [88], the presence of unique microbes between humans and mice may pose a limitation on the generation of humanized gnotobiotic mouse models, particularly if these bacteria have host-specific physiological influences; for example, murine-segmented filamentous bacteria (SFB) [89]. Some host-dependent immune maturation might not occur after cross-species FMT, i.e., only mouse microbiota transplants, but neither those of humans nor rats, could induce immune cell expansions in germ-free mice [89]. Gut microbiota of mice generates higher concentrations of lactate than that of humans, although humans still produce higher levels of some short chain fatty acids (SCFAs), such as acetate and propionate [90]. So, in arranging microbiota studies using humanized gnotobiotic mouse models, selecting the appropriate mouse strains to reflect both the objectives of the study, the ability of the microbiota to colonize the gut, and the possible composition of microbiota and metabolite in mice gut after transplantation is an important issue in study design [82].

Regarding the preparation of human feces for implantation, the effect of temperature and atmospheric conditions on fresh samples varied depending on the donor, but storage for $>24 \mathrm{~h}$ at $37^{\circ} \mathrm{C}$ resulted in significant decline in the genera Lactobacillus, Enterococcus, Ruminococcus, and Eubacterium proliferated, whereas it differed for many Ruminococcaceae family members, such as Ruminococcus and Faecalibacterium [91]. So human fecal samples for FMT in mice should be fresh samples or samples prepared in maltodextrintrehalose solutions stored at $-80^{\circ} \mathrm{C}$ before rapid thawing at $37^{\circ} \mathrm{C}$ to preserve maximum flora resemblance [82,91].

\section{Conclusions}

To replenish the disturbed microbiota, the most efficient and commonly used method is FMT. FMT is listed as the alternative therapeutic choice for refractory or recurrent CDI in many guidelines. The drawback of FMT is the instable therapeutic effect because of the changing and diverse component of the donor's microbiota. How to uniform the therapeutic effect of FMT is a major challenge now. Some commercialized liquid suspensions of donor microbiota, such as RBX2660, have been used. In the future, commercialized uniform donor microbiota might provide more efficient and more consistent therapeutic effects of FMT in treating CDI.

A mixture of probiotics, such as Lactobacillus species or S. boulardii, has been utilized extensively in preventing CDIs, and aims at less disturbance in the microbiota to prevent 
CDI recurrence after therapy cessation. Other than the preventive effect, it is a pity the evidence of the therapeutic effect of mixtures of probiotics in CDI is still limited. The disturbance on microbiota, from initial antibiotic exposure, subsequent infection by C. difficile, to finally treatment with metronidazole or vancomycin, could be expected to be very "severe" and a "disorder". The limited therapeutic effect of mixtures of probiotics with only a few probiotic strains on this "severe" microbiota disturbance could be anticipated. Unless more potent probiotics mixtures are discovered, the effect of mixtures of probiotics in CDI remains a preventive instead of therapeutic role.

Numerous newly developed therapeutic agents aim at preserving microbiota during CDI treatment to prevent disease recurrence and might be useful in clinical patients with rCDIs. Less disruption in microbiota provides more chance for microbiota to recover and decrease the recurrent rate of CDI after treatment cessation.

It is a pity that, besides FMT, there are no better ways to replenish the disturbed microbiota up to now. Though some probiotics or drugs have been shown to increase some beneficial bacteria in the microbiota, these "treated" microbiota are still quite different from the "healthy" microbiota, especially in the bacterial diversity. Drugs that can replenish the disturbed microbiota, instead of using FMT, would be the target of new drug development in the future.

Author Contributions: C.-W.C., P.-J.T., C.-C.L., W.-C.K. and Y.-P.H. designed the experiments, performed the experiments, analyzed the data, and participated in the writing of the manuscript. All authors have read and agreed to the published version of the manuscript.

Funding: The present study was supported by research grants from the Ministry of Health and Welfare (MOHW105-CDC-C-114-122113), the Ministry of Science and Technology (MOST 108-2321B-006-004 and 109-2314-B-006-089-MY), and National Cheng Kung University Hospital (NCKUH11004029), Taiwan.

Institutional Review Board Statement: Not applicable.

Informed Consent Statement: Not applicable.

Data Availability Statement: Data available in a publicly accessible repository.

Conflicts of Interest: All authors report no conflicts of interest relevant to this article.

\section{References}

1. Kuijper, E.J.; van Dissel, J.T.; Wilcox, M.H. Clostridium difficile: Changing epidemiology and new treatment options. Curr. Opin. Infect. Dis. 2007, 20, 376-383. [CrossRef] [PubMed]

2. Zhang, R.F.; Man, Y.X.; Bai, Y.Y.; Shao, C.H.; Liu, C.M.; Wang, C.H.; Lei, Y.X.; Wang, Y.; Jin, Y. Molecular characterization of Clostridioides difficile ribotype 027 in a major Chinese hospital. J. Microbiol. Immunol. Infect. 2021. [CrossRef] [PubMed]

3. Lee, J.C.; Hung, Y.P.; Tsai, B.Y.; Tsai, P.J.; Ko, W.C. Severe Clostridium difficile infections in intensive care units: Diverse clinical presentations. J. Microbiol. Immunol. Infect. 2020. [CrossRef] [PubMed]

4. $\quad$ Chang, T.H.; Hsu, W.Y.; Yang, T.I.; Lu, C.Y.; Hsueh, P.R.; Chen, J.M.; Lee, P.I.; Huang, L.M.; Chang, L.Y. Increased age and proton pump inhibitors are associated with severe Clostridium difficile infections in children. J. Microbiol. Immunol. Infect. 2020, 53, 578-584. [CrossRef] [PubMed]

5. Hung, Y.P.; Lee, J.C.; Tsai, B.Y.; Wu, J.L.; Liu, H.C.; Liu, H.C.; Lin, H.J.; Tsai, P.J.; Ko, W.C. Risk factors of Clostridium difficileassociated diarrhea in hospitalized adults: Vary by hospitalized duration. J. Microbiol. Immunol. Infect. 2019. [CrossRef]

6. McDonald, L.C.; Gerding, D.N.; Johnson, S.; Bakken, J.S.; Carroll, K.C.; Coffin, S.E.; Dubberke, E.R.; Garey, K.W.; Gould, C.V.; Kelly, C.; et al. Clinical Practice Guidelines for Clostridium difficile Infection in Adults and Children: 2017 Update by the Infectious Diseases Society of America (IDSA) and Society for Healthcare Epidemiology of America (SHEA). Clin. Infect. Dis. 2018, 66, 987-994. [CrossRef] [PubMed]

7. Lewis, B.B.; Buffie, C.G.; Carter, R.A.; Leiner, I.; Toussaint, N.C.; Miller, L.C.; Gobourne, A.; Ling, L.; Pamer, E.G. Loss of MicrobiotaMediated Colonization Resistance to Clostridium difficile Infection With Oral Vancomycin Compared With Metronidazole. J. Infect. Dis. 2015, 212, 1656-1665. [CrossRef]

8. Kelly, C.P.; LaMont, J.T. Clostridium difficile-more difficult than ever. N. Engl. J. Med. 2008, 359, 1932-1940. [CrossRef] [PubMed]

9. Umemura, T.; Ota, A.; Mutoh, Y.; Norizuki, C.; Mizuno, T.; Kozaki, K.; Ikeda, Y.; Ichihara, T. Efficacy of prolonged tapered and pulsed vancomycin regimen on recurrent Clostridioides difficile infection in the Japanese setting: A case control study. J. Pharm. Health Care Sci. 2019, 5, 19. [CrossRef] 
10. Giuffre, M.; Campigotto, M.; Campisciano, G.; Comar, M.; Croce, L.S. A story of liver and gut microbes: How does the intestinal flora affect liver disease? A review of the literature. Am. J. Physiol. Gastrointest. Liver Physiol. 2020, 318, G889-G906. [CrossRef]

11. Giuffre, M.; Moretti, R.; Campisciano, G.; da Silveira, A.B.M.; Monda, V.M.; Comar, M.; Di Bella, S.; Antonello, R.M.; Luzzati, R.; Croce, L.S. You Talking to Me? Says the Enteric Nervous System (ENS) to the Microbe. How Intestinal Microbes Interact with the ENS. J. Clin. Med. 2020, 9, 3705. [CrossRef] [PubMed]

12. Kim, Y.G.; Sakamoto, K.; Seo, S.U.; Pickard, J.M.; Gillilland, M.G., 3rd; Pudlo, N.A.; Hoostal, M.; Li, X.; Wang, T.D.; Feehley, T.; et al. Neonatal acquisition of Clostridia species protects against colonization by bacterial pathogens. Science 2017, 356, 315-319. [CrossRef]

13. Davenport, E.R.; Mizrahi-Man, O.; Michelini, K.; Barreiro, L.B.; Ober, C.; Gilad, Y. Seasonal variation in human gut microbiome composition. PLoS ONE 2014, 9, e90731. [CrossRef] [PubMed]

14. Wuethrich, I.; Pelzer, B.W.; Khodamoradi, Y.; Vehreschild, M.J. The role of the human gut microbiota in colonization and infection with multidrug-resistant bacteria. Gut Microbes 2021, 13, 1-13. [CrossRef] [PubMed]

15. Ooijevaar, R.E.; van Beurden, Y.H.; Terveer, E.M.; Goorhuis, A.; Bauer, M.P.; Keller, J.J.; Mulder, C.J.J.; Kuijper, E.J. Update of treatment algorithms for Clostridium difficile infection. Clin. Microbiol. Infect. 2018, 24, 452-462. [CrossRef]

16. Mintz, M.; Khair, S.; Grewal, S.; LaComb, J.F.; Park, J.; Channer, B.; Rajapakse, R.; Bucobo, J.C.; Buscaglia, J.M.; Monzur, F.; et al. Longitudinal microbiome analysis of single donor fecal microbiota transplantation in patients with recurrent Clostridium difficile infection and/or ulcerative colitis. PLoS ONE 2018, 13, e0190997. [CrossRef]

17. Chilton, C.H.; Pickering, D.S.; Freeman, J. Microbiologic factors affecting Clostridium difficile recurrence. Clin. Microbiol. Infect. 2018, 24, 476-482. [CrossRef] [PubMed]

18. Jiang, Z.D.; Ajami, N.J.; Petrosino, J.F.; Jun, G.; Hanis, C.L.; Shah, M.; Hochman, L.; Ankoma-Sey, V.; DuPont, A.W.; Wong, M.C.; et al. Randomised clinical trial: Faecal microbiota transplantation for recurrent Clostridum difficile infection-fresh, or frozen, or lyophilised microbiota from a small pool of healthy donors delivered by colonoscopy. Aliment Pharmacol. Ther. 2017, 45, 899-908. [CrossRef]

19. Staley, C.; Kaiser, T.; Vaughn, B.P.; Graiziger, C.; Hamilton, M.J.; Kabage, A.J.; Khoruts, A.; Sadowsky, M.J. Durable Long-Term Bacterial Engraftment following Encapsulated Fecal Microbiota Transplantation To Treat Clostridium difficile Infection. mBio 2019, 10. [CrossRef]

20. Jiang, Z.D.; Jenq, R.R.; Ajami, N.J.; Petrosino, J.F.; Alexander, A.A.; Ke, S.; Iqbal, T.; DuPont, A.W.; Muldrew, K.; Shi, Y.; et al. Safety and preliminary efficacy of orally administered lyophilized fecal microbiota product compared with frozen product given by enema for recurrent Clostridium difficile infection: A randomized clinical trial. PLoS ONE 2018, 13, e0205064. [CrossRef]

21. Fareed, S.; Sarode, N.; Stewart, F.J.; Malik, A.; Laghaie, E.; Khizer, S.; Yan, F.; Pratte, Z.; Lewis, J.; Immergluck, L.C. Applying fecal microbiota transplantation (FMT) to treat recurrent Clostridium difficile infections (rCDI) in children. PeerJ 2018, 6, e4663. [CrossRef] [PubMed]

22. Camacho-Ortiz, A.; Gutierrez-Delgado, E.M.; Garcia-Mazcorro, J.F.; Mendoza-Olazaran, S.; Martinez-Melendez, A.; Palau-Davila L.; Baines, S.D.; Maldonado-Garza, H.; Garza-Gonzalez, E. Randomized clinical trial to evaluate the effect of fecal microbiota transplant for initial Clostridium difficile infection in intestinal microbiome. PLoS ONE 2017, 12, e0189768. [CrossRef] [PubMed]

23. Staley, C.; Vaughn, B.P.; Graiziger, C.T.; Singroy, S.; Hamilton, M.J.; Yao, D.; Chen, C.; Khoruts, A.; Sadowsky, M.J. Community dynamics drive punctuated engraftment of the fecal microbiome following transplantation using freeze-dried, encapsulated fecal microbiota. Gut Microbes 2017, 8, 276-288. [CrossRef]

24. Jalanka, J.; Mattila, E.; Jouhten, H.; Hartman, J.; de Vos, W.M.; Arkkila, P.; Satokari, R. Long-term effects on luminal and mucosal microbiota and commonly acquired taxa in faecal microbiota transplantation for recurrent Clostridium difficile infection. BMC Med. 2016, 14, 155. [CrossRef] [PubMed]

25. Millan, B.; Park, H.; Hotte, N.; Mathieu, O.; Burguiere, P.; Tompkins, T.A.; Kao, D.; Madsen, K.L. Fecal Microbial Transplants Reduce Antibiotic-resistant Genes in Patients With Recurrent Clostridium difficile Infection. Clin. Infect. Dis. 2016, 62, 1479-1486. [CrossRef] [PubMed]

26. Shankar, V.; Hamilton, M.J.; Khoruts, A.; Kilburn, A.; Unno, T.; Paliy, O.; Sadowsky, M.J. Species and genus level resolution analysis of gut microbiota in Clostridium difficile patients following fecal microbiota transplantation. Microbiome $2014,2,13$. [CrossRef]

27. Jouhten, H.; Ronkainen, A.; Aakko, J.; Salminen, S.; Mattila, E.; Arkkila, P.; Satokari, R. Cultivation and Genomics Prove Long-Term Colonization of Donor's Bifidobacteria in Recurrent Clostridioides difficile Patients Treated With Fecal Microbiota Transplantation. Front. Microbiol. 2020, 11, 1663. [CrossRef]

28. Girotra, M.; Garg, S.; Anand, R.; Song, Y.; Dutta, S.K. Fecal Microbiota Transplantation for Recurrent Clostridium difficile Infection in the Elderly: Long-Term Outcomes and Microbiota Changes. Dig. Dis. Sci. 2016, 61, 3007-3015. [CrossRef]

29. Dutta, S.K.; Girotra, M.; Garg, S.; Dutta, A.; von Rosenvinge, E.C.; Maddox, C.; Song, Y.; Bartlett, J.G.; Vinayek, R.; Fricke, W.F. Efficacy of combined jejunal and colonic fecal microbiota transplantation for recurrent Clostridium difficile Infection. Clin. Gastroenterol. Hepatol. 2014, 12, 1572-1576. [CrossRef]

30. Song, Y.; Garg, S.; Girotra, M.; Maddox, C.; von Rosenvinge, E.C.; Dutta, A.; Dutta, S.; Fricke, W.F. Microbiota dynamics in patients treated with fecal microbiota transplantation for recurrent Clostridium difficile infection. PLoS ONE 2013, 8, e81330. [CrossRef] 
31. Brown, J.R.; Flemer, B.; Joyce, S.A.; Zulquernain, A.; Sheehan, D.; Shanahan, F.; O'Toole, P.W. Changes in microbiota composition, bile and fatty acid metabolism, in successful faecal microbiota transplantation for Clostridioides difficile infection. BMC Gastroenterol. 2018, 18, 131. [CrossRef]

32. Anand, R.; Song, Y.; Garg, S.; Girotra, M.; Sinha, A.; Sivaraman, A.; Phillips, L.; Dutta, S.K. Effect of Aging on the Composition of Fecal Microbiota in Donors for FMT and Its Impact on Clinical Outcomes. Dig. Dis. Sci. 2017, 62, 1002-1008. [CrossRef] [PubMed]

33. Konturek, P.C.; Koziel, J.; Dieterich, W.; Haziri, D.; Wirtz, S.; Glowczyk, I.; Konturek, K.; Neurath, M.F.; Zopf, Y. Successful therapy of Clostridium difficile infection with fecal microbiota transplantation. J. Physiol. Pharmacol. 2016, 67, 859-866. [CrossRef]

34. Langdon, A.; Schwartz, D.J.; Bulow, C.; Sun, X.; Hink, T.; Reske, K.A.; Jones, C.; Burnham, C.D.; Dubberke, E.R.; Dantas, G.; et al. Microbiota restoration reduces antibiotic-resistant bacteria gut colonization in patients with recurrent Clostridioides difficile infection from the open-label PUNCH CD study. Genome Med. 2021, 13, 28. [CrossRef] [PubMed]

35. Mullish, B.H.; McDonald, J.A.K.; Pechlivanis, A.; Allegretti, J.R.; Kao, D.; Barker, G.F.; Kapila, D.; Petrof, E.O.; Joyce, S.A.; Gahan, C.G.M.; et al. Microbial bile salt hydrolases mediate the efficacy of faecal microbiota transplant in the treatment of recurrent Clostridioides difficile infection. Gut 2019, 68, 1791-1800. [CrossRef] [PubMed]

36. Monaghan, T.; Mullish, B.H.; Patterson, J.; Wong, G.K.; Marchesi, J.R.; Xu, H.; Jilani, T.; Kao, D. Effective fecal microbiota transplantation for recurrent Clostridioides difficile infection in humans is associated with increased signalling in the bile acidfarnesoid X receptor-fibroblast growth factor pathway. Gut Microbes 2019, 10, 142-148. [CrossRef] [PubMed]

37. Solbach, P.; Chhatwal, P.; Woltemate, S.; Tacconelli, E.; Buhl, M.; Gerhard, M.; Thoeringer, C.K.; Vehreschild, M.; Jazmati, N.; Rupp, J.; et al. BaiCD gene cluster abundance is negatively correlated with Clostridium difficile infection. PLoS ONE 2018, 13, e0196977. [CrossRef] [PubMed]

38. Seekatz, A.M.; Theriot, C.M.; Rao, K.; Chang, Y.M.; Freeman, A.E.; Kao, J.Y.; Young, V.B. Restoration of short chain fatty acid and bile acid metabolism following fecal microbiota transplantation in patients with recurrent Clostridium difficile infection. Anaerobe 2018, 53, 64-73. [CrossRef]

39. Ianiro, G.; Valerio, L.; Masucci, L.; Pecere, S.; Bibbo, S.; Quaranta, G.; Posteraro, B.; Curro, D.; Sanguinetti, M.; Gasbarrini, A.; et al. Predictors of failure after single faecal microbiota transplantation in patients with recurrent Clostridium difficile infection: Results from a 3-year, single-centre cohort study. Clin. Microbiol. Infect. 2017, 23, 337.e1-e3. [CrossRef]

40. Cheng, Y.W.; Phelps, E.; Ganapini, V.; Khan, N.; Ouyang, F.; Xu, H.; Khanna, S.; Tariq, R.; Friedman-Moraco, R.J.; Woodworth, M.H.; et al. Fecal microbiota transplantation for the treatment of recurrent and severe Clostridium difficile infection in solid organ transplant recipients: A multicenter experience. Am. J. Transplant. 2018, 19, 501-511. [CrossRef]

41. DeFilipp, Z.; Bloom, P.P.; Torres Soto, M.; Mansour, M.K.; Sater, M.R.A.; Huntley, M.H.; Turbett, S.; Chung, R.T.; Chen, Y.B.; Hohmann, E.L. Drug-Resistant E. coli Bacteremia Transmitted by Fecal Microbiota Transplant. N. Engl. J. Med. 2019, 381, 2043-2050. [CrossRef] [PubMed]

42. Pochapin, M. The effect of probiotics on Clostridium difficile diarrhea. Am. J. Gastroenterol. 2000, 95, S11-S13. [CrossRef]

43. Goldenberg, J.Z.; Yap, C.; Lytvyn, L.; Lo, C.K.; Beardsley, J.; Mertz, D.; Johnston, B.C. Probiotics for the prevention of Clostridium difficile-associated diarrhea in adults and children. Cochrane Database Syst. Rev. 2017, 12, CD006095. [CrossRef] [PubMed]

44. Schell, M.A.; Karmirantzou, M.; Snel, B.; Vilanova, D.; Berger, B.; Pessi, G.; Zwahlen, M.C.; Desiere, F.; Bork, P.; Delley, M.; et al. The genome sequence of Bifidobacterium longum reflects its adaptation to the human gastrointestinal tract. Proc. Natl. Acad. Sci. USA 2002, 99, 14422-14427. [CrossRef]

45. Trejo, F.M.; Minnaard, J.; Perez, P.F.; De Antoni, G.L. Inhibition of Clostridium difficile growth and adhesion to enterocytes by Bifidobacterium supernatants. Anaerobe 2006, 12, 186-193. [CrossRef] [PubMed]

46. Gargari, G.; Taverniti, V.; Balzaretti, S.; Ferrario, C.; Gardana, C.; Simonetti, P.; Guglielmetti, S. Consumption of a Bifidobacterium bifidum Strain for 4 Weeks Modulates Dominant Intestinal Bacterial Taxa and Fecal Butyrate in Healthy Adults. Appl. Environ. Microbiol. 2016, 82, 5850-5859. [CrossRef]

47. Barker, A.K.; Duster, M.; Valentine, S.; Hess, T.; Archbald-Pannone, L.; Guerrant, R.; Safdar, N. A randomized controlled trial of probiotics for Clostridium difficile infection in adults (PICO). J. Antimicrob. Chemother. 2017, 72, 3177-3180. [CrossRef]

48. Maziade, P.J.; Pereira, P.; Goldstein, E.J. A Decade of Experience in Primary Prevention of Clostridium difficile Infection at a Community Hospital Using the Probiotic Combination Lactobacillus acidophilus CL1285, Lactobacillus casei LBC80R, and Lactobacillus rhamnosus CLR2 (Bio-K+). Clin. Infect. Dis. 2015, 60 (Suppl. S2), S144-S147. [CrossRef]

49. Kujawa-Szewieczek, A.; Adamczak, M.; Kwiecien, K.; Dudzicz, S.; Gazda, M.; Wiecek, A. The Effect of Lactobacillus plantarum 299v on the Incidence of Clostridium difficile Infection in High Risk Patients Treated with Antibiotics. Nutrients 2015, 7, 10179-10188. [CrossRef] [PubMed]

50. Hickson, M.; D’Souza, A.L.; Muthu, N.; Rogers, T.R.; Want, S.; Rajkumar, C.; Bulpitt, C.J. Use of probiotic Lactobacillus preparation to prevent diarrhoea associated with antibiotics: Randomised double blind placebo controlled trial. BMJ 2007, 335, 80. [CrossRef]

51. Swidsinski, A.; Loening-Baucke, V.; Verstraelen, H.; Osowska, S.; Doerffel, Y. Biostructure of fecal microbiota in healthy subjects and patients with chronic idiopathic diarrhea. Gastroenterology 2008, 135, 568-579. [CrossRef] [PubMed]

52. Koon, H.W.; Su, B.; Xu, C.; Mussatto, C.C.; Tran, D.H.; Lee, E.C.; Ortiz, C.; Wang, J.; Lee, J.E.; Ho, S.; et al. Probiotic Saccharomyces boulardii CNCM I-745 prevents outbreak-associated Clostridium difficile-associated cecal inflammation in hamsters. Am. J. Physiol. Gastrointest Liver Physiol. 2016, 311, G610-G623. [CrossRef] 
53. Surawicz, C.M.; McFarland, L.V.; Greenberg, R.N.; Rubin, M.; Fekety, R.; Mulligan, M.E.; Garcia, R.J.; Brandmarker, S.; Bowen, K.; Borjal, D.; et al. The search for a better treatment for recurrent Clostridium difficile disease: Use of high-dose vancomycin combined with Saccharomyces boulardii. Clin. Infect. Dis. 2000, 31, 1012-1017. [CrossRef] [PubMed]

54. McFarland, L.V.; Surawicz, C.M.; Greenberg, R.N.; Fekety, R.; Elmer, G.W.; Moyer, K.A.; Melcher, S.A.; Bowen, K.E.; Cox, J.L.; Noorani, Z.; et al. A randomized placebo-controlled trial of Saccharomyces boulardii in combination with standard antibiotics for Clostridium difficile disease. JAMA 1994, 271, 1913-1918. [CrossRef] [PubMed]

55. Li, X.; Kang, Y.; Huang, Y.; Xiao, Y.; Song, L.; Lu, S.; Ren, Z. A strain of Bacteroides thetaiotaomicron attenuates colonization of Clostridioides difficile and affects intestinal microbiota and bile acids profile in a mouse model. Biomed. Pharmacother. 2021, 137, 111290. [CrossRef]

56. Deng, H.; Yang, S.; Zhang, Y.; Qian, K.; Zhang, Z.; Liu, Y.; Wang, Y.; Bai, Y.; Fan, H.; Zhao, X.; et al. Bacteroides fragilis Prevents Clostridium difficile Infection in a Mouse Model by Restoring Gut Barrier and Microbiome Regulation. Front. Microbiol. 2018, 9, 2976. [CrossRef] [PubMed]

57. Mountzouris, K.C.; McCartney, A.L.; Gibson, G.R. Intestinal microflora of human infants and current trends for its nutritional modulation. Br. J. Nutr. 2002, 87, 405-420. [CrossRef] [PubMed]

58. Oka, K.; Osaki, T.; Hanawa, T.; Kurata, S.; Sugiyama, E.; Takahashi, M.; Tanaka, M.; Taguchi, H.; Kamiya, S. Establishment of an Endogenous Clostridium difficile Rat Infection Model and Evaluation of the Effects of Clostridium butyricum MIYAIRI 588 Probiotic Strain. Front. Microbiol. 2018, 9, 1264. [CrossRef]

59. Seki, H.; Shiohara, M.; Matsumura, T.; Miyagawa, N.; Tanaka, M.; Komiyama, A.; Kurata, S. Prevention of antibiotic-associated diarrhea in children by Clostridium butyricum MIYAIRI. Pediatr. Int. 2003, 45, 86-90. [CrossRef]

60. Nagamine, T.; Matsumoto, Y.; Nakamura, M. Combination probiotics may prevent Clostridium difficile infection among elderly patients undergoing an orthopedic surgery. Biosci. Microbiota Food Health 2019, 38, 31-33. [CrossRef]

61. Khoruts, A. Targeting the microbiome: From probiotics to fecal microbiota transplantation. Genome Med. 2018, 10, 80. [CrossRef] [PubMed]

62. Britton, R.A.; Hoffmann, D.E.; Khoruts, A. Probiotics and the Microbiome-How Can We Help Patients Make Sense of Probiotics? Gastroenterology 2021, 160, 614-623. [CrossRef] [PubMed]

63. Vyas, V.; Mian, S.; Paolino, K.; Siddique, Z. Lactobacillus masticator abscess after probiotics consumption. Proc. (Bayl. Univ. Med. Cent.) 2020, 34, 93-94. [CrossRef] [PubMed]

64. Chiang, M.C.; Chen, C.L.; Feng, Y.; Chen, C.C.; Lien, R.; Chiu, C.H. Lactobacillus rhamnosus sepsis associated with probiotic therapy in an extremely preterm infant: Pathogenesis and a review for clinicians. J. Microbiol. Immunol. Infect. 2020. [CrossRef] [PubMed]

65. Sendil, S.; Shrimanker, I.; Mansoora, Q.; Goldman, J.; Nookala, V.K. Lactobacillus rhamnosus Bacteremia in an Immunocompromised Renal Transplant Patient. Cureus 2020, 12, e6887. [CrossRef] [PubMed]

66. Yamaguchi, T.; Konishi, H.; Aoki, K.; Ishii, Y.; Chono, K.; Tateda, K. The gut microbiome diversity of Clostridioides difficileinoculated mice treated with vancomycin and fidaxomicin. J. Infect. Chemother 2020, 26, 483-491. [CrossRef]

67. Ajami, N.J.; Cope, J.L.; Wong, M.C.; Petrosino, J.F.; Chesnel, L. Impact of Oral Fidaxomicin Administration on the Intestinal Microbiota and Susceptibility to Clostridium difficile Colonization in Mice. Antimicrob. Agents Chemother 2018, 62. [CrossRef]

68. Guery, B.; Menichetti, F.; Anttila, V.J.; Adomakoh, N.; Aguado, J.M.; Bisnauthsing, K.; Georgopali, A.; Goldenberg, S.D.; Karas, A.; Kazeem, G.; et al. Extended-pulsed fidaxomicin versus vancomycin for Clostridium difficile infection in patients 60 years and older (EXTEND): A randomised, controlled, open-label, phase 3b/4 trial. Lancet Infect. Dis. 2018, 18, 296-307. [CrossRef]

69. Louie, T.J.; Cannon, K.; Byrne, B.; Emery, J.; Ward, L.; Eyben, M.; Krulicki, W. Fidaxomicin preserves the intestinal microbiome during and after treatment of Clostridium difficile infection (CDI) and reduces both toxin reexpression and recurrence of CDI. Clin. Infect. Dis. 2012, 55 (Suppl. S2), S132-S142. [CrossRef]

70. Qian, X.; Yanagi, K.; Kane, A.V.; Alden, N.; Lei, M.; Snydman, D.R.; Vickers, R.J.; Lee, K.; Thorpe, C.M. Ridinilazole, a narrow spectrum antibiotic for treatment of Clostridioides difficile infection, enhances preservation of microbiota-dependent bile acids. Am. J. Physiol. Gastrointest Liver Physiol 2020, 319, G227-G237. [CrossRef]

71. Vickers, R.J.; Tillotson, G.S.; Nathan, R.; Hazan, S.; Pullman, J.; Lucasti, C.; Deck, K.; Yacyshyn, B.; Maliakkal, B.; Pesant, Y.; et al. Efficacy and safety of ridinilazole compared with vancomycin for the treatment of Clostridium difficile infection: A phase 2, randomised, double-blind, active-controlled, non-inferiority study. Lancet Infect Dis. 2017, 17, 735-744. [CrossRef]

72. Gerding, D.N.; Cornely, O.A.; Grill, S.; Kracker, H.; Marrast, A.C.; Nord, C.E.; Talbot, G.H.; Buitrago, M.; Gheorghe Diaconescu, I.; Murta de Oliveira, C.; et al. Cadazolid for the treatment of Clostridium difficile infection: Results of two double-blind, placebo-controlled, non-inferiority, randomised phase 3 trials. Lancet Infect Dis. 2019, 19, 265-274. [CrossRef]

73. Chilton, C.H.; Crowther, G.S.; Baines, S.D.; Todhunter, S.L.; Freeman, J.; Locher, H.H.; Athanasiou, A.; Wilcox, M.H. In vitro activity of cadazolid against clinically relevant Clostridium difficile isolates and in an in vitro gut model of C. difficile infection. J. Antimicrob Chemother 2014, 69, 697-705. [CrossRef] [PubMed]

74. Stewart, D.B. Anti-Sense Antibiotic Agents as Treatment for Bacterial Infections. Surg. Infect. 2018, 19, 831-835. [CrossRef] [PubMed]

75. Hegarty, J.P.; Krzeminski, J.; Sharma, A.K.; Guzman-Villanueva, D.; Weissig, V.; Stewart, D.B., Sr. Bolaamphiphile-based nanocomplex delivery of phosphorothioate gapmer antisense oligonucleotides as a treatment for Clostridium difficile. Int. J. Nanomedicine 2016, 11, 3607-3619. [CrossRef] [PubMed] 
76. Roberts, A.K.; Harris, H.C.; Smith, M.; Giles, J.; Polak, O.; Buckley, A.M.; Clark, E.; Ewin, D.; Moura, I.B.; Spitall, W.; et al. A Novel, Orally Delivered Antibody Therapy and Its Potential to Prevent Clostridioides difficile Infection in Pre-clinical Models. Front. Microbiol. 2020, 11, 578903. [CrossRef]

77. Dzunkova, M.; D'Auria, G.; Xu, H.; Huang, J.; Duan, Y.; Moya, A.; Kelly, C.P.; Chen, X. The Monoclonal Antitoxin Antibodies (Actoxumab-Bezlotoxumab) Treatment Facilitates Normalization of the Gut Microbiota of Mice with Clostridium difficile Infection. Front. Cell Infect. Microbiol. 2016, 6, 119. [CrossRef]

78. Jones, J.A.; Prior, A.M.; Marreddy, R.K.R.; Wahrmund, R.D.; Hurdle, J.G.; Sun, D.; Hevener, K.E. Small-Molecule Inhibition of the C. difficile FAS-II Enzyme, FabK, Results in Selective Activity. ACS Chem. Biol. 2019, 14, 1528-1535. [CrossRef]

79. Wilcox, M.H.; Gerding, D.N.; Poxton, I.R.; Kelly, C.; Nathan, R.; Birch, T.; Cornely, O.A.; Rahav, G.; Bouza, E.; Lee, C.; et al. Bezlotoxumab for Prevention of Recurrent Clostridium difficile Infection. N. Engl. J. Med. 2017, 376, 305-317. [CrossRef]

80. Lundberg, R.; Toft, M.F.; August, B.; Hansen, A.K.; Hansen, C.H. Antibiotic-treated versus germ-free rodents for microbiota transplantation studies. Gut Microbes 2016, 7, 68-74. [CrossRef]

81. Hazenberg, M.P.; Bakker, M.; Verschoor-Burggraaf, A. Effects of the human intestinal flora on germ-free mice. J. Appl. Bacteriol. 1981, 50, 95-106. [CrossRef] [PubMed]

82. Park, J.C.; Im, S.H. Of men in mice: The development and application of a humanized gnotobiotic mouse model for microbiome therapeutics. Exp. Mol. Med. 2020, 52, 1383-1396. [CrossRef] [PubMed]

83. Raibaud, P.; Ducluzeau, R.; Dubos, F.; Hudault, S.; Bewa, H.; Muller, M.C. Implantation of bacteria from the digestive tract of man and various animals into gnotobiotic mice. Am. J. Clin. Nutr. 1980, 33, 2440-2447. [CrossRef] [PubMed]

84. Mallett, A.K.; Bearne, C.A.; Rowland, I.R.; Farthing, M.J.; Cole, C.B.; Fuller, R. The use of rats associated with a human faecal flora as a model for studying the effects of diet on the human gut microflora. J. Appl. Bacteriol. 1987, 63, 39-45. [CrossRef] [PubMed]

85. Round, J.L.; Palm, N.W. Causal effects of the microbiota on immune-mediated diseases. Sci. Immunol. 2018, 3. [CrossRef] [PubMed]

86. Walter, J.; Armet, A.M.; Finlay, B.B.; Shanahan, F. Establishing or Exaggerating Causality for the Gut Microbiome: Lessons from Human Microbiota-Associated Rodents. Cell 2020, 180, 221-232. [CrossRef] [PubMed]

87. Steele, J.; Feng, H.; Parry, N.; Tzipori, S. Piglet models of acute or chronic Clostridium difficile illness. J. Infect. Dis. 2010, 201, 428-434. [CrossRef]

88. Krych, L.; Hansen, C.H.; Hansen, A.K.; van den Berg, F.W.; Nielsen, D.S. Quantitatively different, yet qualitatively alike: A meta-analysis of the mouse core gut microbiome with a view towards the human gut microbiome. PLoS ONE 2013, 8, e62578. [CrossRef]

89. Chung, H.; Pamp, S.J.; Hill, J.A.; Surana, N.K.; Edelman, S.M.; Troy, E.B.; Reading, N.C.; Villablanca, E.J.; Wang, S.; Mora, J.R.; et al. Gut immune maturation depends on colonization with a host-specific microbiota. Cell 2012, 149, 1578-1593. [CrossRef]

90. Ley, R.E.; Backhed, F.; Turnbaugh, P.; Lozupone, C.A.; Knight, R.D.; Gordon, J.I. Obesity alters gut microbial ecology. Proc. Natl. Acad. Sci. USA 2005, 102, 11070-11075. [CrossRef]

91. Burz, S.D.; Abraham, A.L.; Fonseca, F.; David, O.; Chapron, A.; Beguet-Crespel, F.; Cenard, S.; Le Roux, K.; Patrascu, O.; Levenez, F.; et al. A Guide for Ex Vivo Handling and Storage of Stool Samples Intended for Fecal Microbiota Transplantation. Sci. Rep. 2019, 9, 8897. [CrossRef] [PubMed] 